\title{
DERIVATIVES OF CENTELLA ASIATICA USED AGAINST LEPROSY
}

$C$

\section{Chemical Constitution of Asiaticoside}

VENTELLA asiatica (Urban) (Hydrocotyle asia. tica L. is a plant of the family Umbelliferæ. Intusions of this plant are utilized in India and Madagascar against leprosy; it is also mentioned in the French Pharmacopœia of 1884.

Bontems ${ }^{1}$ reported in 1942 the isolation from Centella asiatica of a crystalline glycoside which he called asiaticoside. Devanne and Razafimahéry ${ }^{2}$ proposed the formula $\mathrm{C}_{21} \mathrm{H}_{34} \mathrm{O}_{8}$ for this glycoside, and stated that hydrolysis gives one molecule of glucose and an amorphous aglucone $\mathrm{C}_{15} \mathrm{H}_{24} \mathrm{O}_{3}$.

We have recently begun a study of the chemical constitution of asiaticoside, using crystalline material produced on a pilot-plant scale in Tananarive (Madagascar) $^{3}$. After three recrystallizations from dilute alcohol we obtained colourless prisms, m.p. $230-233^{\circ}$ (decomp.), $[\alpha] D=-14^{\circ}$ (in alcohol). Elementary analysis and the composition of the products of hydrolysis are in agreement with the formula $\mathrm{C}_{54} \mathrm{H}_{90} \mathrm{O}_{23}$, or $\mathrm{C}_{54} \mathrm{H}_{88} \mathrm{O}_{23}$ for asiaticoside (found: $\mathrm{C}$, $58 \cdot 18,58 \cdot 38 ; \mathrm{H}, 8 \cdot 32,8 \cdot 25$; calculated for $\mathrm{C}_{54} \mathrm{H}_{90} \mathrm{O}_{23}$ : C, $58.54 ; \mathrm{H}, 8 \cdot 21$ per cent).

Acid or alkaline hydrolysis of asiaticoside proceeds remarkably rapidly and gives an aglycone and two different sugars. These have been identified as glucose and rhamnose, by preparation of crystelline derivatives, and by partition chromatography on paper. A quantitative determination of rhamnose by the method of Nicolet and Shinn ${ }^{5}$ indicates the presence of two molecules of rhamnose for one molecule of asiaticoside (found, 28.98 per cent rhamnose ; calculated, $29 \cdot 63$ per cent). The optical rotation of the sugar mixture formed by hydrolysis and the reducing power as determined by the method of Bertrand ${ }^{6}$ show that asiaticoside contains two molecules of D-glucose and two molecules of L-rhamnose.

The aglycone of asiaticoside is a triterpene acid, $\mathrm{C}_{30} \mathrm{H}_{48} \mathrm{O}_{5}$ or $\mathrm{C}_{30} \mathrm{H}_{50} \mathrm{O}_{5}$, which we propose to call 'asiatic acid'. The hydrolysis of asiaticoside thus proceeds as shown by the following equation :

$$
\mathrm{C}_{64} \mathrm{H}_{90} \mathrm{O}_{23}+4 \mathrm{H}_{2} \mathrm{O}=\mathrm{C}_{30} \mathrm{H}_{50} \mathrm{O}_{5}+\underset{\text { glucose }}{2 \mathrm{C}_{6} \mathrm{H}_{12} \mathrm{O}_{6}}+\underset{\text { rhamnose. }}{2 \mathrm{C}_{6} \mathrm{H}_{12} \mathrm{O}_{5}}
$$

Free asiatic acid is very difficult to crystallize (m.p. $240-244^{\circ}$, after purification through its sodium salt, m.p. $310^{\circ}$ ), but its methyl ester, obtained by methylation with diazomethane or dimethyl sulphate, crystallizes readily (needles, m.p. $225^{\circ}$ (corr.), $[\alpha]_{D}=$ $+52^{\circ}$ (in alcohol) and analyses correctly for $\mathrm{C}_{31} \mathrm{H}_{50} \mathrm{O}_{5}$ or $\mathrm{C}_{31} \mathrm{H}_{52} \mathrm{O}_{5}$ (found: $\mathrm{C}, 73.83,73.99 ; \mathrm{H}, 10 \cdot 29$, $10 \cdot 30$; $\mathrm{OCH}_{3}, 6 \cdot 14$ per cent (Weiler, Oxford); C, $73.71 ; \mathrm{H}, 10.13 ; \mathrm{OCH}_{3}, 6 \cdot 35$ per cent (Manser, Zurich); $\mathrm{C}_{31} \mathrm{H}_{50} \mathrm{O}_{5}$ requires $\mathrm{C}, 74.03$; $\mathrm{H}, 10.05$; $\mathrm{OCH}_{3}, 6.17$ per cent; $\mathrm{C}_{31} \mathrm{H}_{52} \mathrm{O}_{5}$ requires $\mathrm{C}, 73.74$; $\mathrm{H}, 10 \cdot 40$; $\mathrm{OCH}_{3}, 6 \cdot 14$ per cent). The Zeisel determinations confirm beyond doubt the size of the molecule.

Dehydrogenation of asiatic acid with palladium. charcoal or selenium gives a hydrocarbon, the picrate and styphnate of which show no depression of melting point with the corresponding derivatives of sapotalene (1:2:7-trimethylnaphthalene), the typical dehydrogenation product of the triterpenes?. Typical colour reactions of the triterpenes are also positiv $\epsilon^{8}$.
Molting points, optical rotations and chemical and physical behaviour of different derivatives of asiatic acid show great similarity with those of other triterpene acids of the $\beta$-amyrin group; thus all evidence is in favour of the hypothesis that the carbon skeleton of asiatic acid is the same as that of $\beta$-amyrin (ef. Haworth ${ }^{2}$, Ruzicka ${ }^{7}$ ).

Two of the oxygen atoms of asiatic acid are accounted for by the carboxyl group; the three remaining ones form hydroxyl groups. Two of these are in a 1:2-glycol group, as oxidation with lead tetra-acetate proceeds readily at room temperature and gives a substance precipitating with $2: 4$-dinitrophenylhydrazine. The presence of such a $1: 2$-glycol group seems to be a new feature for natural triterpene acids (cf. refs. 10, 11). The composition of crystalline acetates obtained from asiatic methyl ester is still under investigation.

The presence of a double bond in asiatic acid is indicated by the formation of a bromo-lactone, similar to that of oleanolic acid or hederagenin; tetranitromethane gives a slight colour with asiatic acid or its methyl ester.

The methyl ester of asiatic acid is very difficult to saponify, like that of similar triterpene acids containing a tertiary carboxyl group. On treating the methyl ester, m.p. $225^{\circ}$, with 15 per cent hydro. chloric acid, it is isomerized to a new ester, m.p. $170^{\circ}$.

By chromatography on alumina of the crude methyl ester, m.p. $225^{\circ}$, we have isolated a small quantity of a dimethyl ester, $\mathrm{C}_{32} \mathrm{H}_{52} \mathrm{O}_{5}$, m.p. $262^{\circ}$ (found : $\mathrm{C}$, $73.71 ; \mathrm{H}, 10 \cdot 23 ; \mathrm{OCH}_{3}, 12 \cdot 3$. $\mathrm{C}_{32} \mathrm{H}_{32} \mathrm{O}_{5}$ requires C, $74 \cdot 35 ; \mathrm{H}, 10 \cdot 17 ; \mathrm{OCH}_{3}, 12 \cdot 28$ per cent).

As asiaticoside is a neutral substance, it seems that the sugars are attached to the carboxyl group; the ease of saponification suggests that all four sugar molecules are attached in this way. Lythgoe and Trippett have made analogous observations with centelloside ${ }^{10}$.

A comparison of our substance with those prepared in Cambridge from Centella asiatica from Ceylon ${ }^{10,11}$ has shown that we have certainly different compounds in hand. We are very glad to state that we are keeping in contact with Dr. Lythgoe for the study of these triterpene acids.

\section{P. Botteau \\ A. Buzas \\ E. LEDERER \\ J. PoLONSKY}

Institut de Biologie

Physico-Chimique,

13 Rue Pierre Curie, Paris 5ème.

Aug. 24.

' Bontems, J. E., Gaz. Méd. Madagascar, 5, 29 (1942).

¿ Devanne, J., and Razafimahéry, R., Gaz. Méd. Madagascar, 5 34 (1942).

${ }^{3}$ Grimes, C., and Boiteau, P., sème Rapp. Ann. Soc. Parc Botan. et Zool. Tananarive (Tananarive, 1947).

${ }^{4}$ Partridge, S. M., Biochem. J., 42, 238 (1948).

- Nicolet, B. F., and Shinn, L. A., J. Amer. Chem. Soc. 63, 1456 (1941).

- Bertrand, G., Bull. Soc. chim. (3), 15, 627 (1896).

'Ruzicka, L. "Les Prix Nobel", 177 (1945). We wish to thank Prof. Ruzicka for the opportunity of having some of our substances analysed in his Institute.

${ }^{8}$ Noller, C. R.. Smith, R. A., Harris, G. H., and Walker, J. W., J. Amer. Chem. Soc., e4. 3047 (1942)

' Haworth, R. D., Ann. Rep. Ch m. Soc., 34, 327 (1937).

${ }^{20}$ Lythgoe, B., and Trippett, S. (see following communication).

${ }^{11}$ Lythgoe, B., and Bhattacharyya, S.C. (see following communication). 